\title{
Editorial
}

\section{Blood cancers: Flowing the right way!}

Starting from recognition and chemotherapeutic treatment of hematolymphoid malignancies, the science of blood diseases has seen major advances in recent years, especially identification of molecular pathways involved in pathogenesis and development of targeted therapies with high efficacy and limited toxicities even in relapsed/refractory diseases.

Chronic myeloid leukemia (CML) has been a prototype of success of targeted therapy. CML is uniformly associated with translocation between long arms of chromosome 9 and 22 (t9:22) (q32:q11) leading to the formation of Philadelphia chromosome and a chimeric fusion gene BCR-ABL and its abnormal protein product which is central to pathogenesis of CML. BCR-ABL has intrinsic tyrosine kinase activity and is an attractive target of tyrosine kinase inhibitors (TKIs). ${ }^{\left[{ }^{11}\right.}$ The World has seen the magic of TKIs in changing the picture of CML treatment and outcome. Similar success story has been witnessed in acute promyelocytic leukemia by drugs targeting PML-RARA fusion gene. ${ }^{\mid 2]}$ There are many more drug targets being identified and explored in clinical trials.

Decade of 2000s saw a major change in the outcome of lymphoma patients with introduction of anti-CD20 antibody (rituximab) in frontline treatment of CD20 expressing B-cell malignancies. Similarly, monoclonal antibodies targeting CD22, CD30 has been found to be successful in salvaging multiple line treated and refractory patients with lymphomas expressing respective antigen. ${ }^{[3]}$

Myeloma similarly, after success of newer proteasome inhibitors and antiangiogenic drugs, has seen many new drug targets such as HDAC, SLAMF7, and CD38. Vorinostat, elotuzumab, and daratumumab, respectively, target HDAC, SLAMF7, and CD38 and are effective in multiline treated myeloma. ${ }^{[4]}$

Major pathogenic pathways or associated gene aberrations have been identified for most of the hematological malignancies and are being explored for being drug targets. A major breakthrough is the development of small molecule inhibitors of downstream of B-cell receptor (BCR) pathways. Ibrutinib (a Bruton's TKI) and idelalisib (a PI3K inhibitor as well as BCR signaling inhibitor) are promising new targeted therapies not only for relapsed refractory B-cell malignancies but also in upfront settings in certain high-risk diseases such as chronic lymphocytic leukemia with del $17 p{ }^{\mid 5]}$

A breakthrough in therapeutics is identification of the role of evasion of immune checkpoints by advancing malignancies by expression of programmed death ligand-1 (PDL-1) on the surface of tumor cells interacting with programmed death-1 (PD-1) molecule on activated lymphocytes. In trials, anti-PD-1 or anti-PDL-1 drugs have shown promising results even in advanced refractory Hodgkin lymphoma. ${ }^{[6]}$

One of the major advances in field of hematology is evolution of cellular therapies over the past five decades, most popularly in the form of allogeneic stem cell transplantation (allo-SCT) from a treatment offered to terminally ill to now in the first line for many of high-risk malignancies and marrow failure syndromes. Despite availability of large voluntary donor pool/registries, nearly $30 \%$ of patients in need of transplant could not find a suitably matched donor. There is additional cost involved in procurement of matched unrelated donor stem cells or unrelated cord cells. Moreover, the time taken to procuring unrelated stem cells is also one of the major constrains for the patient in dire need of allo-SCT. Haploidentical donors are readily available in family for most of the patients but was not routinely offered to most of patients due to high treatment-related mortality and limited availability of ex vivo graft manipulation techniques. Haploidentical SCT has seen major paradigm shift from the use of sophisticated and expensive techniques of ex vivo graft manipulation to selective in vivo alloreactive T-cell depletion by cheaper high-dose posttransplant cyclophosphamide (PTCy). ${ }^{[7]}$ This way the survival posthaploidentical SCT is similar to matched donor allo-SCT with added advantage of better immune recovery and lesser opportunistic infections. ${ }^{[8]}$ Haploidentical SCT has already an established and popular modality of allo-SCT in most parts of the world after the success of PTCy-based regimes.

Future of hematology sees an era of molecularly defined entities, targeted therapies, and probably cellular therapies to provide antitumor immunity. ${ }^{|9|}$ Chimeric antigen receptor (CAR) directed engineered T-cells (CAR-T) have shown durable responses in patients with refractory hematological malignancies. CAR-T cells are long-lived cells and provide 
long-lasting immunity against tumor. Both autologous and allogeneic CAR-T cells are in trial.

Current issue of Asian journal of clinical oncology is encompassing reviews on hematological malignancies with a focus of recent developments.

\section{Narendra Agarwal, Rayaz Ahmed, Dinesh BhuRANi}

Department of Medical Oncology, Division of Hematolo-oncology Rajiv Gandhi Cancer Institute and Research Centre, New Delhi, India

Address for correspondence: Dr. Dinesh Bhurani, Department of Medical Oncology, Division of Hematology and Oncology, Rajiv Gandhi Cancer Institute and Research Centre, Sector-5, Rohini, New Delhi - 110 085, India. E-mail: bhurani.dinesh@rgcirc.org

\section{References}

1. O'Brien SG, Guilhot F, Larson RA, Gathmann I, Baccarani M, Cervantes $\mathrm{F}$, et al. Imatinib compared with interferon and low-dose cytarabine for newly diagnosed chronic-phase chronic myeloid leukemia. N Engl J Med 2003;348:994-1004.

2. Advani SH. All trans retinoic acid. J Assoc Physicians India 1995;Suppl 3:65-6.

3. Bello C, Sotomayor EM. Monoclonal antibodies for B-cell lymphomas: Rituximab and beyond. Hematology Am Soc Hematol Educ Program 2007:233-42.

4. van de Donk NW, Moreau P, Plesner T, Palumbo A, Gay F, Laubach JP, et al. Clinical efficacy and management of monoclonal antibodies targeting CD38 and SLAMF7 in multiple myeloma. Blood 2016;127:681-95.
5. Vitale C, Burger JA. Chronic lymphocytic leukemia therapy: New targeted therapies on the way. Expert Opin Pharmacother 2016. [Epub ahead of print].

6. Ansell SM, Lesokhin AM, Borrello I, Halwani A, Scott EC, Gutierrez M, et al. PD-1 blockade with nivolumab in relapsed or refractory Hodgkin's lymphoma. N Engl J Med 2015;372:311-9.

7. Fuchs EJ. HLA-haploidentical blood or marrow transplantation with high-dose, post-transplantation cyclophosphamide. Bone Marrow Transplant 2015;50 Suppl 2:S31-6.

8. Bashey A, Zhang X, Jackson K, Brown S, Ridgeway M, Solh M, et al. Comparison of outcomes of hematopoietic cell transplants from T-replete haploidentical donors using post-transplantation cyclophosphamide with 10 of 10 HLA-A, -B, -C, -DRB1, and -DQB1 allele-matched unrelated donors and HLA-identical sibling donors: A Multivariable analysis including disease risk index. Biol Blood Marrow Transplant 2016;22:125-33.

9. Li S, Yang Z, Shen J, Shan J, Qian C. Adoptive therapy with CAR redirected $T$ cells for hematological malignancies. Sci China Life Sci 2016. [Epub ahead of print].

This is an open access article distributed under the terms of the Creative Commons Attribution-NonCommercial-ShareAlike 3.0 License, which allows others to remix, tweak, and build upon the work non-commercially, as long as the author is credited and the new creations are licensed under the identical terms.

\begin{tabular}{|l|c|}
\hline \multicolumn{2}{|c|}{ Access this article online } \\
Website: & Quick Response Code \\
www.asjo.in & \\
\hline &
\end{tabular}

How to cite this article: Agarwal N, Ahmed R, Bhurani D. Blood cancers: Flowing the right way!. Asian J Oncol 2016;2:1-2. 